\title{
Trends in Ophthalmology Resident Operative Experience and the Early Impact of the COVID-19 Pandemic
} \author{
John R. Potts III, MD \\ ${ }^{1}$ Casey Eye Institute, Oregon Health Science University, Department \\ of Ophthalmology 515 SW Campus Drive, Portland, Oregon 97239 \\ 2 Departments of Ophthalmology and Visual Sciences and Neurology, \\ University of lowa Hospitals and Clinics, Hawkins Dr, lowa City, lowa 52242 \\ 3 Operative Care Division, Veterans Affairs Portland Health Care \\ System, 3710 SW US Veterans Hospital Rd, Portland, OR 97239 \\ ${ }^{4}$ Sue Anschutz-Rodgers Eye Center, Department of Ophthalmology \\ 1675 Aurora Ct, Aurora, Colorado 80045
}

Andreas K. Lauer, MD ${ }^{1}$ Sophia M. Chung, MD² Daniel C. Tu, MD, PhD ${ }^{1,3}$ Jeffrey R. SooHoo, MD

Address for correspondence Andreas K. Lauer, MD, Casey Eye Institute, Oregon Health Science University, 515 Southwest Campus Drive, Portland, OR 97239 (e-mail: lauera@ohsu.edu).

J Acad Ophthalmol 2021;13:e200-e209.

\section{Abstract \\ Keywords \\ - ACGME \\ - case logs \\ - COVID-19 \\ - ophthalmology \\ - pandemic \\ - residency \\ - resident \\ - surgery \\ - surgical education}

Purpose This study aimed to evaluate trends in ophthalmology resident operative experience and the early impact of the novel coronavirus disease 2019 (COVID-19) pandemic.

Design Present study is a retrospective analysis of the Accreditation Council for Graduate Medical Education (ACGME) Case Log System.

Participants Anonymized graduating resident case logs from 2011 to 2020 academic years (AYs) were examined for this study.

Methods Regression analysis for each procedure category was performed to identify trends between 2011 and 2019 AYs. Unpaired two-tailed $t$-test compared 2018 to 2019 and 2019 to 2020 AY's for each category surgeon (S) and as surgeon and assistant $(S+A)$.

Main Outcome Measures Mean and median cases as $(S)$ and $(S+A)$ during 2011 to 2019 AYs. Comparison between 2018 to 2019 and 2019 to 2020 AY's for each category as $(S)$ and $(S+A)$ to evaluate the impact of the COVID-19 pandemic.

Results Total ophthalmology procedures as $(S)$ rose from a mean of 479.6 to 601.3 $\left(p<0.001 ; R^{2}=0.96 ; \Delta /\right.$ year $\left.=16.9\right)$ and a median of 444 to $537\left(p<0.001 ; R^{2}=0.97 ; \Delta /\right.$ year $=13.1)$. Total procedures as $(S+A)$ rose from a mean of 698.1 to $768(p<0.01$; $R^{2}=0.83 ; \Delta /$ year $\left.=9.07\right)$ and a median of 677 to $734\left(p<0.05 ; R^{2}=0.61 ; \Delta /\right.$ year $\left.=6.64\right)$. Cataract procedures as (S) rose from a mean of 152.8 to $208\left(p<0.001 ; R^{2}=0.99 ; \Delta /\right.$ year $=7.98)$ and a median of 146 to $197\left(p<0.001 ; R^{2}=0.97 ; \Delta /\right.$ year $\left.=7.87\right)$. Cataract procedures as both $(\mathrm{S}+\mathrm{A})$ rose from a mean 231.4 to $268.7\left(p<0.001 ; R^{2}=0.95 ; \Delta /\right.$ year $=5.5)$ and a median of 213 to $254\left(p<0.001 ; R^{2}=0.93 ; \Delta /\right.$ year $\left.=5.33\right)$. Between 2018 to 2019 and 2019 to $2020 \mathrm{AYs}$, the first pandemic year was associated with significant received

May 19, 2021

accepted after revision

August 19, 2021
DOI https://doi.org/ $10.1055 / \mathrm{s}-0041-1740052$. ISSN 2475-4757.

\footnotetext{
(c) 2021. The Author(s).

This is an open access article published by Thieme under the terms of the Creative Commons Attribution-NonDerivative-NonCommercial-License, permitting copying and reproduction so long as the original work is given appropriate credit. Contents may not be used for commercial purposes, or adapted, remixed, transformed or built upon. (https://creativecommons.org/ licenses/by-nc-nd/4.0/) Thieme Medical Publishers, Inc., 333 Seventh Avenue, 18th Floor, New York, NY 10001, USA
} 
reductions in total procedures $(601.3-533.7[p<0.0001])$ as $(S)$ and 768.0 to 694.4 $(p<0.0001)$ as $(S+A)$, cataract surgery $(208-162.2[p<0.0001])$ as $(S)$ and 268.7 to 219.1 $(p<0.0001)$ as $(S+A)$, and glaucoma surgery $(16.3-14.2[p=0.0068])$ as $(S)$ and 25.6 to $22.6(p=0.0063)$ as $(S+A)$.

Conclusion During 2011 to 2019 AYs, cataract, intravitreal injections, glaucoma, and total procedures increased significantly. During the early period of the COVID-19 pandemic (2019-2020 AY), national halting of elective procedures had a precipitous effect on resident cataract surgery experience to volumes similar to 2013 to $2014 \mathrm{AY}$ where the mean was twice the current required minimum number. With few exceptions, other procedure volumes remained stable.

Severe acute respiratory syndrome-coronavirus-2 (SARS-CoV-2) was first identified in Wuhan, China, in December 2019 and led to the ongoing novel coronavirus disease 2019 (COVID-19) pandemic. In January 2020, the World Health Organization declared the outbreak a Public Health Emergency of International Concern. A pandemic was declared in March 2020. COVID-19 spread quickly and pervasively. ${ }^{1-3}$ On a global scale, communities and their economies were disrupted and infection, illness, and fatalities rose sharply. ${ }^{1,4}$ The COVID-19 pandemic also widely disrupted surgical practice raising numerous concerns such as intraoperative viral transmission risk, workforce and staffing issues, procedural prioritization and rationing, as well as threatening surgical education. ${ }^{5,6}$ In the spring of 2020, most of the hospital systems in the United States halted elective surgeries to prepare for a large influx of acutely ill patients and to prevent the collapse of the U.S. health care system. The reduction in surgical cases disrupted learning experiences for many residents including those in ophthalmology. ${ }^{7-11}$

The Accreditation Council for Graduate Medical Education (ACGME) is a private, not-for-profit organization that sets standards for U.S. graduate medical education programs. Accreditation decisions are made by a specialtyspecific review committee (RC) that assesses program-compliance with these standards. The ACGME's Accreditation Data System (ADS) is a web-based software system that collects and organizes accreditation data for all training institutions and their programs. The ACGME Case Log System is an application within ADS to collect and document trainees' clinical experiences. For surgical specialties like ophthalmology, these data are grouped into specialtyspecific categories and are used as one of several performance indicators of training programs. ${ }^{12-14}$ Each graduating resident must have performed and/or assisted in a minimum number of essential operative cases and case categories as established by the RC for ophthalmology and all residents must have equivalent educational opportunities. Training programs access the system to review the information logged by their trainees and refine the programs' educational curricula to meet program requirements. Achievement of the required minimum numbers is one of numerous indicators of the surgical experience that a program provides and is not considered a standalone indicator of physician competence. ${ }^{15,16}$
In this study, we evaluate graduating ophthalmology residents' ACGME case log numbers from academic year 2011 to 2020 AYs to investigate trends in ophthalmic surgical training, as well as to evaluate the early impact of the COVID-19 pandemic in the 2019 to 2020 AY.

\section{Methods}

The ACGME ophthalmology surgical case logs published from 2011 to 2020 AY at accredited U.S. programs were reviewed. An $\mathrm{AY}$ is defined as a 12-month period starting July 1 through June 30 of the following calendar year. Trends in the mean and median number of cases performed by graduating ophthalmology residents as surgeon (S) and as surgeon and assistant $(\mathrm{S}+\mathrm{A})$ were analyzed. The definition of surgeon and assistant are available on the ACGME Ophthalmology RC web page. ${ }^{16}$ The $\mathrm{RC}$ has defined minimum procedure requirements for experience as (S). For more subspecialized procedures, where further training is expected beyond residency, the RC defined minimum requirements for experience as $(S+A) .{ }^{16}$ The total number of procedures and procedures in the categories of cataract, cornea, keratorefractive, glaucoma, globe trauma, oculoplastics and orbit, retina vitreous, strabismus, and laser surgery were reviewed. Because the category, other retina procedures, was primarily comprised of intravitreal injections, the latter was classified as a unique category. Within the category of laser surgery, yttrium aluminum garnet (YAG) capsulotomy, laser trabeculoplasty, laser iridotomy, panretinal laser photocoagulation, focal laser photocoagulation, and other glaucoma laser procedures were evaluated. In the area of oculoplastics and orbit, there are numerous subcategories; those with significant changes are described. Cornea surgery is subcategorized as keratoplasty and pterygium/conjunctival and other cornea procedures. Cornea surgery was analyzed as a whole and the subcategories were not analyzed due to procedure mapping changes during the study period. Although focal laser photocoagulation is no longer a required procedure, it remains tracked in the case log system and was included in the analysis. Cyclodestructive procedures and other glaucoma laser procedures such as iridoplasty do not have minimum requirements but also continue to be tracked in the case log system.

To identify trends between 2011 to 2012 and 2018 to 2019 AYs, a regression analysis for each procedure category was 
e202 Impact of the COVID-19 Pandemic in Ophthalmology Resident Programs Lauer et al.

performed. To test whether the early phase of the COVID-19 pandemic created a difference in surgical experience, an unpaired two-tailed $t$-test was used to compare 2018 to 2019 and 2019 to 2020 AYs for each category as (S) and $(\mathrm{S}+\mathrm{A})$. The Institutional Review Board/Ethics Committee ruled that approval was not required for this study.

\section{Results}

- Table 1 depicts the trends in median and mean volumes in surgical and laser procedures between 2011 to 2012 and 2018 to 2019 AYs, as well as the mean change between 2018 to 2019 and 2019 to 2020 AYs for roles of $(S)$ and $(S+A)$.

Table 1 Trends in median and mean surgical volume between 2011 to 2012 and 2018 to 2019 AYs, as well as the mean change between 2018 to 2019 AY and 2019 to 2020 AY, for roles of (S) and (S+A) for surgical and laser procedures

\begin{tabular}{|c|c|c|c|c|c|c|c|c|c|c|c|c|}
\hline & & \multicolumn{7}{|c|}{ Surgeon: 2012 through 2019} & \multicolumn{4}{|c|}{ Surgeon: 2020 vs. 2019} \\
\hline & \multicolumn{4}{|c|}{ Median } & \multicolumn{4}{|c|}{ Mean } & & 2019 Mean & 2020 Mean & $p$ \\
\hline & & $\Delta /$ year & $R^{2}$ & $p$ & & $\Delta /$ year & $R^{2}$ & $p$ & & & & \\
\hline Cataract & $\uparrow$ & 7.87 & 0.97 & $<0.0001$ & $\uparrow$ & 7.98 & 0.99 & $<0.0001$ & $\downarrow$ & 208.0 & 162.2 & $<0.0001$ \\
\hline Other cataract & $\downarrow$ & -0.42 & 0.93 & $<0.001$ & $\downarrow$ & -0.44 & 0.97 & $<0.0001$ & & 2.3 & 2.1 & 0.611 \\
\hline Laser surgery & & -1.29 & 0.46 & 0.066 & $\downarrow$ & -2.02 & 0.70 & 0.009 & $\downarrow$ & 101.1 & 92.6 & 0.028 \\
\hline Cornea surgery & & 0.05 & 0.06 & 0.547 & & 0.05 & 0.21 & 0.257 & & 12.7 & 11.6 & 0.059 \\
\hline $\begin{array}{l}\text { Keratorefractive } \\
\text { surgery }\end{array}$ & $\uparrow$ & 0.14 & 0.57 & 0.030 & & 0.1 & 0.30 & 0.163 & & 5.7 & 4.5 & 0.105 \\
\hline Strabismus & $\downarrow$ & -0.36 & 0.71 & 0.008 & $\downarrow$ & -0.47 & 0.82 & 0.002 & & 23.5 & 22.9 & 0.506 \\
\hline Glaucoma & $\uparrow$ & 0.37 & 0.83 & 0.002 & $\uparrow$ & 0.56 & 0.85 & 0.001 & $\downarrow$ & 16.3 & 14.2 & 0.007 \\
\hline Retinal vitreous & & -0.01 & 0.01 & 0.846 & & -0.04 & 0.07 & 0.541 & & 6.4 & 5.4 & 0.068 \\
\hline Other retinal & $\uparrow$ & 6.99 & 0.94 & $<0.0001$ & $\uparrow$ & 11.20 & 0.97 & $<0.0001$ & & 145.4 & 144.4 & 0.912 \\
\hline $\begin{array}{l}\text { Oculoplastic } \\
\text { and orbit }\end{array}$ & & -0.07 & 0.02 & 0.729 & & 0.06 & 0.04 & 0.642 & $\downarrow$ & 70.2 & 64.8 & 0.02 \\
\hline Globe trauma & & 0 & 1 & NS & & -0.05 & 0.09 & 0.481 & & 9.6 & 9.0 & 0.063 \\
\hline \multirow[t]{4}{*}{ All procedures } & $\uparrow$ & 13.10 & 0.97 & $<0.0001$ & $\uparrow$ & 16.94 & 0.96 & $<0.0001$ & $\downarrow$ & 601.3 & 533.7 & $<0.0001$ \\
\hline & & \multicolumn{3}{|c|}{$\begin{array}{l}\text { Regression } \\
\text { analysis/ANOVA }\end{array}$} & & & & & & & & \\
\hline & & \multicolumn{3}{|c|}{$\begin{array}{l}\text { Unpaired } t \text {-test, } \\
\text { two-tailed }\end{array}$} & & & & & & & & \\
\hline & \multicolumn{8}{|c|}{ Surgeon + assistant: 2012 through 2019} & \multicolumn{4}{|c|}{ Surgeon + assistant: 2020 vs. 2019} \\
\hline Cataract & $\uparrow$ & 5.33 & 0.93 & $<0.001$ & $\uparrow$ & 5.50 & 0.95 & $<0.0001$ & $\downarrow$ & 268.7 & 219.1 & $<0.0001$ \\
\hline Other cataract & $\downarrow$ & -0.74 & 0.95 & $<0.0001$ & $\downarrow$ & -0.84 & 0.99 & $<0.0001$ & & 4.6 & 4.4 & 0.746 \\
\hline Laser surgery & $\downarrow$ & -1.57 & 0.69 & 0.010 & $\downarrow$ & -2.37 & 0.77 & 0.004 & $\downarrow$ & 104.7 & 96.4 & 0.0319 \\
\hline Cornea surgery & & -0.21 & 0.48 & 0.056 & & -0.18 & 0.41 & 0.089 & & 23.9 & 22.5 & 0.059 \\
\hline $\begin{array}{l}\text { Keratorefractive } \\
\text { surgery }\end{array}$ & & 0.08 & 0.16 & 0.334 & & 0.14 & 0.11 & 0.411 & $\downarrow$ & 14.1 & 11.9 & 0.007 \\
\hline Strabismus & $\downarrow$ & -1.49 & 0.95 & $<0.0001$ & $\downarrow$ & -1.67 & 0.96 & $<0.0001$ & & 32.1 & 32.0 & 0.938 \\
\hline Glaucoma & $\downarrow$ & -0.31 & 0.50 & 0.049 & & 0.01 & 0.00 & 0.961 & $\downarrow$ & 25.6 & 22.6 & 0.006 \\
\hline Retinal vitreous & $\downarrow$ & -0.64 & 0.63 & 0.018 & $\downarrow$ & -0.63 & 0.83 & 0.002 & & 26.6 & 26.0 & 0.595 \\
\hline Other retinal & $\uparrow$ & 6.50 & 0.92 & $<0.001$ & $\uparrow$ & 10.85 & 0.97 & $<0.0001$ & & 147.3 & 146.6 & 0.938 \\
\hline $\begin{array}{l}\text { Oculoplastic } \\
\text { and orbit }\end{array}$ & & -0.87 & 0.29 & 0.167 & $\downarrow$ & -1.37 & 0.92 & 0.000 & & 109.4 & 102.4 & 0.071 \\
\hline Globe trauma & $\downarrow$ & -0.25 & 0.54 & 0.038 & $\downarrow$ & -0.35 & 0.63 & 0.019 & & 11.1 & 10.4 & 0.070 \\
\hline \multirow[t]{3}{*}{ All procedures } & $\uparrow$ & 6.64 & 0.61 & 0.023 & $\uparrow$ & 9.07 & 0.83 & 0.002 & $\downarrow$ & 768.0 & 694.4 & $<0.0001$ \\
\hline & & \multicolumn{3}{|c|}{$\begin{array}{l}\text { Regression } \\
\text { analysis/ANOVA }\end{array}$} & & & & & & & & \\
\hline & & \multicolumn{3}{|c|}{$\begin{array}{l}\text { Unpaired } t \text {-test, two- } \\
\text { tailed }\end{array}$} & & & & & & & & \\
\hline
\end{tabular}

Abbreviations: ANOVA, analysis of variance; AY, academic year; NS, not significant; S, surgeon; S $\mathrm{A}$, surgeon and assistant. 


\section{Trends between 2011-2012 and 2018-2019 Academic Years}

Between 2011 to 2012 and 2018 to 2019 AYs, the total ophthalmology procedures as $(S)$ rose from a mean of 479.6 to $601.3\left(p<0.001 ; R^{2}=0.96 ; \Delta /\right.$ year $\left.=16.9\right)$ and a median of 444 to $537\left(p<0.001 ; R^{2}=0.97 ; \Delta /\right.$ year $\left.=13.1\right)$. Total procedures as $(S+A)$ rose from a mean of 698.1 to 768 $\left(p<0.01 ; R^{2}=0.83 ; \Delta /\right.$ year $\left.=9.07\right)$ and a median of 677 to $734\left(p<0.05 ; R^{2}=0.61 ; \Delta /\right.$ year $\left.=6.64\right)$.

\section{Incisional Surgery}

Cataract procedures as $(\mathrm{S})$ rose from a mean of 152.8 to 208 $\left(p<0.001 ; R^{2}=0.99 ; \Delta /\right.$ year $\left.=7.98\right)$ and a median of 146 to $197\left(p<0.001 ; R^{2}=0.97 ; \Delta /\right.$ year $\left.=7.87\right)$. Cataract procedures as both $(\mathrm{S}+\mathrm{A})$ rose from a mean 231.4 to 268.7 $\left(p<0.001 ; R^{2}=0.95 ; \Delta /\right.$ year $\left.=5.5\right)$ and a median of 213 to $254\left(p<0.001 ; R^{2}=0.93 ; \Delta /\right.$ year $\left.=5.33\right)$. Minimum requirement is $86(\mathrm{~S})$.

Cornea surgery as $(S)$ remained stable with means between 12 and $12.7\left(p=0.26 ; R^{2}=0.21 ; \Delta /\right.$ year $\left.=0.04\right)$ and medians between 9 and $10\left(p=0.26 ; R^{2}=0.21 ; \Delta /\right.$ year $=0.04$ ) procedures annually. Cornea surgery as $(S+A)$ remained stable as well with means between 23.9 and $25.6\left(p=0.41 ; R^{2}=0.11 ; \Delta /\right.$ year $\left.=0.14\right)$ and medians between 21 and $23\left(p=0.056 ; R^{2}=0.48 ; \Delta /\right.$ year $\left.=-0.21\right)$ procedures annually. Minimum requirement for keratoplasty is $5(\mathrm{~S}+\mathrm{A})$ and for pterygium/conjunctival and other cornea is $3(\mathrm{~S})$.

Keratorefractive procedures as $(\mathrm{S})$ remained stable with means between 5.1 and $6.5\left(p=0.16 ; R^{2}=0.30 ; \Delta /\right.$ year $\left.=0.1\right)$ and medians between 1 and $2\left(p=0.03 ; R^{2}=0.57 ; \Delta /\right.$ year $=0.14$ ) procedures annually. Keratorefractive procedures as $(\mathrm{S}+\mathrm{A})$ remained stable with means between 13.8 and 14.1 $\left(p=0.41 ; R^{2}=0.11 ; \Delta /\right.$ year $\left.=0.14\right)$ and medians between 9 and $10\left(p=0.33 ; R^{2}=0.16 ; \Delta /\right.$ year $\left.=0.08\right)$ procedures annually. Minimum requirement is $6(\mathrm{~S}+\mathrm{A})$.

Strabismus procedures as $(S)$ declined from a mean of 26.1 to 23.5 ( $p=0.002 ; R^{2}=0.82 ; \Delta /$ year $\left.=-0.47\right)$ and median of 22 to $19\left(p<0.01 ; R^{2}=0.71 ; \Delta /\right.$ year $\left.=-0.36\right)$. Strabismus procedures as $(\mathrm{S}+\mathrm{A})$ declined from a mean of 42.1 to 32.1 $\left(p<0.001 ; R^{2}=0.96 ; \Delta /\right.$ year $\left.=-1.67\right)$ and a median of 36 to $27\left(p<0.001 ; R^{2}=0.95 ; \Delta /\right.$ year $\left.=-1.49\right)$. Minimum requirement is $10(\mathrm{~S})$.

Glaucoma procedures as $(\mathrm{S})$ rose from a mean of 12.2 to $16.3\left(p=0.001 ; R^{2}=0.85 ; \Delta /\right.$ year $\left.=-0.56\right)$ and a median of 10 to $13\left(p=0.002 ; R^{2}=0.83 ; \Delta /\right.$ year $\left.=0.36\right)$. Glaucoma procedures as $(\mathrm{S}+\mathrm{A})$ was stable at a mean of 23.6 and 25.6 $\left(p=0.96 ; R^{2}=0.00 ; \Delta /\right.$ year $\left.=0.006\right)$ and a median between 21 and $23\left(p<0.05, R^{2}=0.50 ; \Delta /\right.$ year $\left.=-0.31\right)$. Minimum requirement is $5(\mathrm{~S})$.

Retina-vitreous procedures as $(\mathrm{S})$ remained steady between a mean of 5.5 and $6.6\left(p=0.54 ; R^{2}=0.07 ; \Delta /\right.$ year $=$ $-0.04)$ and a median between 2 and $3\left(p=0.85 ; R^{2}=0.01 ; \Delta /\right.$ year $=-0.01)$. Retina-vitreous procedures as $(S+A)$ decreased slightly from a mean of 29.9 to $26.6(p=0.002$; $R^{2}=0.83 ; \Delta /$ year $\left.=-0.63\right)$ and a median of 24 to 22 $\left(p=0.02 ; R^{2}=0.63 ; \Delta /\right.$ year $\left.=-0.64\right)$. Minimum requirement is $10(\mathrm{~S}+\mathrm{A})$.
Other retinal procedures (primarily intravitreal injection) as $(\mathrm{S})$ rose considerably from a mean of 65.8 to 145.4 $\left(p<0.001 ; R^{2}=0.97 ; \Delta /\right.$ year $\left.=11.2\right)$ with a median of 42 to $96\left(p<0.001 ; R^{2}=0.94 ; \Delta /\right.$ year $\left.=6.99\right)$. The numbers for other retinal procedures as $(S+A)$ are similar with a rise from a mean of 69.5 to $147.3\left(p<0.001 ; R^{2}=0.97 ; \Delta /\right.$ year $=10.84)$ and a median of 46 to $96\left(p<0.001 ; R^{2}=0.92 ; \Delta /\right.$ year $=6.5)$. Minimum requirement is $10(\mathrm{~S})$.

Oculoplastic and orbit procedures as $(S)$ remained steady between a mean of 70 and $72\left(p=0.64 ; R^{2}=0.04 ; \Delta /\right.$ year $=0.06)$ as did the median between 60 and $62(p=0.73$; $R^{2}=0.02 ; \Delta /$ year $\left.=-0.07\right)$. Oculoplastic and orbit procedures as $(\mathrm{S}+\mathrm{A})$ decreased from a mean of 119 to 109.4 $\left(p<0.001 ; R^{2}=0.92 ; \Delta /\right.$ year $\left.=-1.37\right)$ and a median of 107 to $101\left(p=0.171 ; R^{2}=0.29 ; \Delta /\right.$ year $\left.=-0.87\right)$. Minimum requirement is $28(\mathrm{~S})$.

Globe trauma procedures as $(S)$ remained steady between a mean of 8.9 and $10.2\left(p=0.48 ; R^{2}=0.09 ; \Delta /\right.$ year $\left.=-0.05\right)$ as did the median at 8 procedures. Globe trauma procedures as $(\mathrm{S}+\mathrm{A})$ decreased from mean of 13.9 to $11.1(p=0.019$; $R^{2}=0.63 ; \Delta /$ year $\left.=-0.35\right)$ and the median varied between 9 and $11\left(p=0.0385 ; R^{2}=0.54 ; \Delta /\right.$ year $\left.=-0.25\right)$. Minimum requirement is $4(\mathrm{~S})$.

\section{Laser Surgery}

Between 2011 to 2012 and 2018 to 2019 AYs, total laser procedures as $(S)$ declined from a mean of 111.3 to 101.1 $\left(p<0.01 ; R^{2}=0.70 ; \Delta /\right.$ year $\left.=-2.02\right)$ and from a median of 93 to $87\left(p=0.066 ; R^{2}=0.47 ; \Delta /\right.$ year $\left.=-1.29\right)$. Laser procedures as $(\mathrm{S}+\mathrm{A})$ declined from a mean of 116.9 to 96.4 $\left(p<0.001 ; R^{2}=0.84 ; \Delta /\right.$ year $\left.=-2.55\right)$ and a median 98 to 81 in AY 2018 to $2019\left(p=0.002 ; R^{2}=0.78 ; \Delta /\right.$ year $\left.=-1.73\right)$.

YAG laser capsulotomy as (S) increased from a mean of 16 to $24\left(p<0.001 ; R^{2}=0.97 ; \Delta /\right.$ year $\left.=1.05\right)$ and a median of 14 to $20\left(p<0.001 ; R^{2}=0.93 ; \Delta /\right.$ year $\left.=0.89\right)$. YAG laser capsulotomy as $(\mathrm{S}+\mathrm{A})$ increased from a mean 17 to $24(p<0.001$; $R^{2}=0.96 ; \Delta /$ year $\left.=1.02\right)$ and from a median of 15 to 21 $\left(p<0.001 ; R^{2}=0.88 ; \Delta /\right.$ year $\left.=0.79\right)$. Minimum requirement is $5(\mathrm{~S})$.

Laser trabeculoplasty procedures as (S) increased from a mean of 13 to $16\left(p<0.001 ; R^{2}=0.90 ; \Delta /\right.$ year $\left.=0.72\right)$ and a median of 8 to $12\left(p<0.001 ; R^{2}=0.96 ; \Delta /\right.$ year $\left.=0.60\right)$. Laser trabeculoplasty procedures as $(\mathrm{S}+\mathrm{A})$ increased from a mean of 13 to $16\left(p<0.001 ; R^{2}=0.92 ; \Delta /\right.$ year $\left.=0.73\right)$ and median of 9 to $11\left(p<0.001 ; R^{2}=0.93 ; \Delta /\right.$ year $\left.=0.42\right)$. Minimum requirement is $5(\mathrm{~S})$.

Laser iridotomy procedures as $(\mathrm{S})$ was stable at a mean of $15\left(p<0.33 ; R^{2}=0.16 ; \Delta /\right.$ year $\left.=0.07\right)$ and the median in the 12 to 13 range $\left(p=0.33 ; R^{2}=0.16 ; \Delta /\right.$ year $\left.=0.08\right)$. The laser iridotomy procedures as $(\mathrm{S}+\mathrm{A})$ was stable with minimal variation at a mean of $16\left(p=0.49 ; R^{2}=0.08 ; \Delta /\right.$ year $\left.=0.04\right)$ and a median varying between 12 and $14\left(p=0.21 ; R^{2}=0.25\right.$; $\Delta /$ year $=0.14)$. Minimum requirement is $4(\mathrm{~S})$.

Panretinal laser photocoagulation (PRP) as (S) declined from mean 50 to $40\left(p<0.01 ; R^{2}=0.76 ; \Delta /\right.$ year $\left.=-1.88\right)$ and a median of 32 to $23\left(p<0.001 ; R^{2}=0.86 ; \Delta /\right.$ year $\left.=-1.46\right)$. PRP as $(\mathrm{S}+\mathrm{A})$ declined from a mean of 50 to $40(p<0.01$; $R^{2}=0.79 ; \Delta /$ year $\left.=-2.07\right)$ and a median of 34 to 24 
$\left(p<0.001 ; R^{2}=0.86 ; \Delta /\right.$ year $\left.=-1.76\right)$. Minimum requirement is $10(\mathrm{~S})$.

Focal laser photocoagulation as (S) declined significantly from a mean of 15 to $2\left(p<0.001 ; R^{2}=0.96 ; \Delta /\right.$ year $\left.=-2.09\right)$ and median from 10 to zero $\left(p<0.001 ; R^{2}=0.95 ; \Delta /\right.$ year $=$ $-1.54)$. Focal laser photocoagulation as $(\mathrm{S}+\mathrm{A})$ declined from a mean of 16 to $2\left(p<0.001 ; R^{2}=0.96 ; \Delta /\right.$ year $\left.=-2.2\right)$ and a median of 11 to zero in AY 2018 to $2019\left(p<0.001 ; R^{2}=0.97\right.$; $\Delta /$ year $=-1.63)$. Minimum requirement was removed during this time period.

Cyclodestructive procedures as (S) increased slightly from mean of 2 to $3\left(p<0.01 ; R^{2}=0.83 ; \Delta /\right.$ year $\left.=0.17\right)$ and the median remained 1 . The number of cyclodestructive procedures as $(\mathrm{S}+\mathrm{A})$ increased slightly from 3 to $4(p<0.001$; $R^{2}=0.91 ; \Delta /$ year $\left.=0.2\right)$ and the median varied between 1 and 2 . There is no minimum requirement.

Other glaucoma laser procedures including iridoplasty were performed infrequently. The number as $(S)$ declined from a mean of 0.8 to $0.4\left(p<0.01 ; R^{2}=0.84 ; \Delta /\right.$ year $=$ $-0.08)$ and the median remained zero. The number as $(\mathrm{S}+\mathrm{A})$ declined from mean of 0.9 to $0.4\left(p<0.001 ; R^{2}=0.86 ; \Delta /\right.$ year $=-0.09$ ) and the median remained zero. There is no minimum requirement.

\section{Early Impact of the COVID-19 Pandemic}

Between 2018 to 2019 and 2019 to 2020 AYs, significant reductions were recorded in total procedures as both $(\mathrm{S})$ (601.3-533.7, $\quad p<0.0001)$ and $(\mathrm{S}+\mathrm{A}) \quad(768.0-694.4$, $p<0.0001)$, as (S) $(208-162.2, p<0.0001)$ and $(\mathrm{S}+\mathrm{A})$
(268.7 to 219.1, $p<0.0001$ ), and glaucoma surgery as ( $\mathrm{S}$ ) $(16.3-14.2, p=0.0068)$ and $(\mathrm{S}+\mathrm{A})(25.6-22.6, p=0.0063)$.

For keratorefractive procedures, no significant change as (S) was noted, but a significant reduction as $(\mathrm{S}+\mathrm{A})$ from 14.1 to $11.9(p=0.0072)$ was noted in this time period. Significant reductions in overall oculoplastic and orbit procedures from 70.2 to $64.8(p=0.02)$ as $(S)$ were noted. No significant overall change was noted as $(\mathrm{S}+\mathrm{A})$ in this time period. Within subcategories, reductions as $(S)$ were noted for chalazia from 8.7 to $7.8(p=0.0212)$ and other orbital surgery from 1.6 to $1.3(p=0.0201)$. Reductions as $(\mathrm{S}+\mathrm{A})$ were noted for eye removal and implant from 4.0 to $3.6(p=0.0387)$, chalazia from 9.7 to $8.7(p=0.0172)$, and other orbital surgery from 5.8 to $5.0(p=0.0244)$. No significant change in corneal, strabismus, retina-vitreous surgery, and other retinal procedures, including intravitreal injections and globe trauma procedures as $(\mathrm{S})$ or $(\mathrm{S}+\mathrm{A})$, were noted.

For laser surgery, significant reductions were noted for total laser procedures from 101.1 to $92.6(p<0.028)$ as (S) and 104.7 to $96.4(p=0.0319)$ as $(\mathrm{S}+\mathrm{A})$, laser iridotomy from 15.6 to $13.6(p=0.002)$ as $(S)$ and 16.2 to $14.2(p=0.002)$ as $(\mathrm{S}+\mathrm{A})$, focal laser photocoagulation from 1.6 to 1.0 $(p=0.002)$ as $(\mathrm{S})$ and 1.7 to $1.2(p=0.0098)$ as $(\mathrm{S}+\mathrm{A})$, and other glaucoma laser procedures from 0.4 to $0.2(p=0.002)$ as $(\mathrm{S})$ and $(\mathrm{S}+\mathrm{A})$. No significant changes in YAG capsulotomy, laser trabeculoplasty, PRP, cyclodestructive procedures as $(\mathrm{S})$ or $(\mathrm{S}+\mathrm{A})$ were noted.

-Fig. 1 depicts procedures where a significant increase in volume occurred between 2011 to 2012 AY and 2018 to 2019

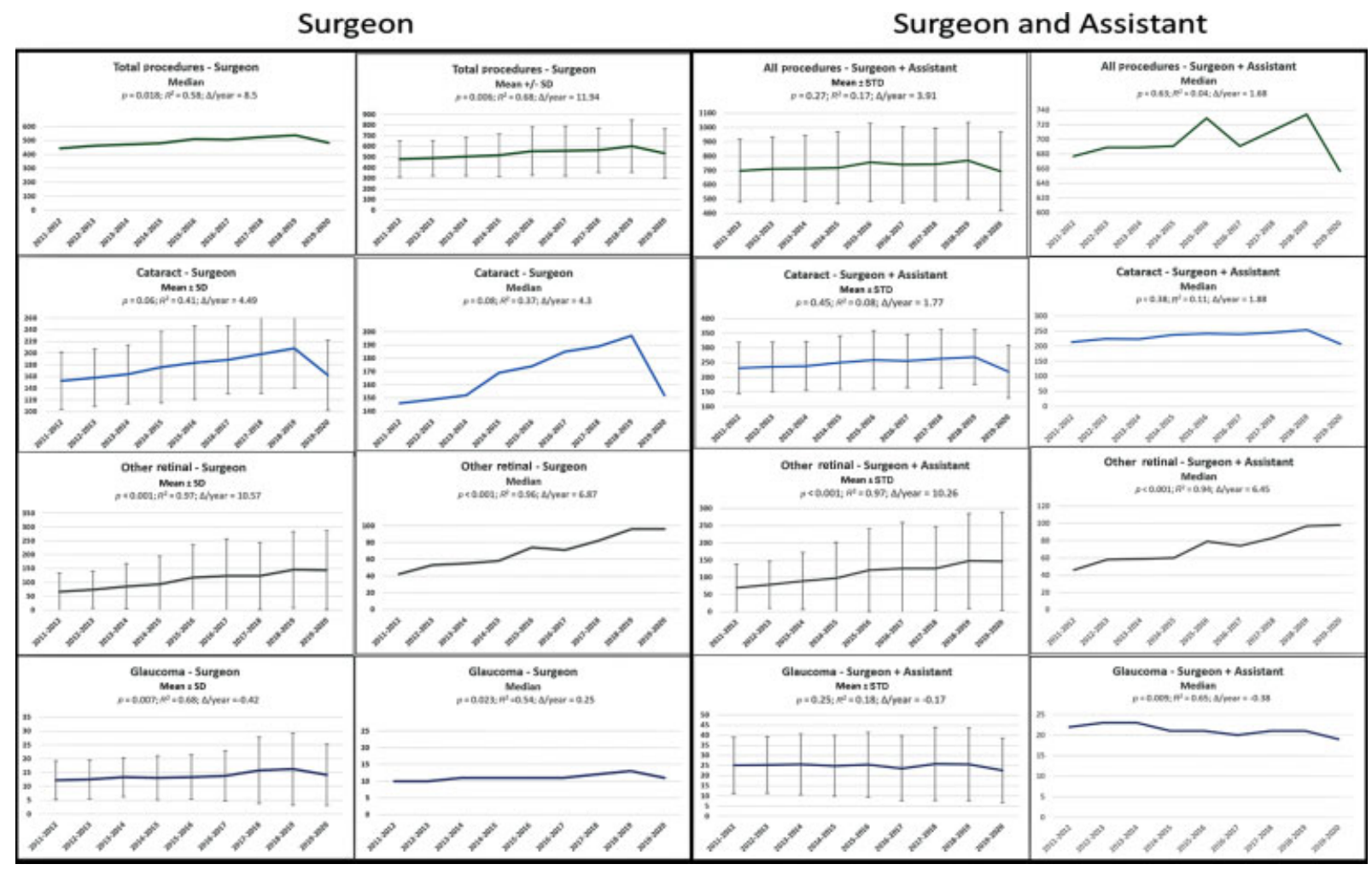

Fig. 1 Total, cataract surgery, other retinal procedure (primarily intravitreal injection) volumes increased between 2011 to $2012 \mathrm{AY}$ and 2018 to 2019 AY for (S) and (S+A). Glaucoma procedures rose significantly for (S) but not for (S + A). Between 2018 to 2019 and 2019 to 2020 AY, significant decreases in total procedures particularly cataract surgery were seen. AY, academic year; S, surgeon; $S+A$, surgeon and assistant. 


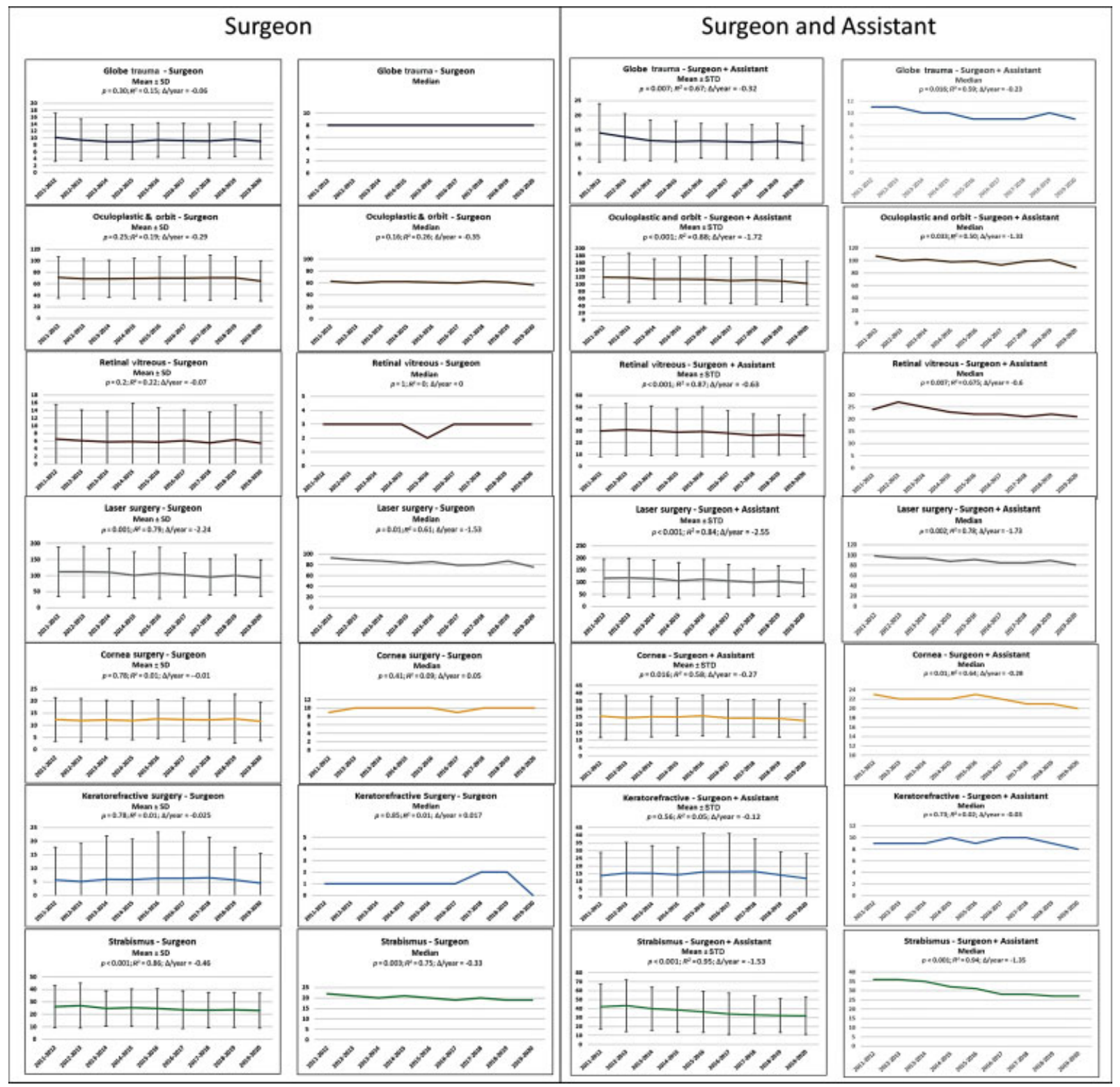

Fig. 2 Procedures whose volume remained stable or gradually decreased are depicted from 2011 to 2012 to 2019 to 2020 AYs. AY, academic year.

AY for total procedures, cataract surgery, and other retinal procedures (primarily intravitreal injection). Glaucoma procedures rose significantly for $(S)$ but not for $(S+A)$. Between 2018 to 2019 and 2019 to 2020 AY, significant decreases in total procedures particularly cataract surgery were seen. In - Fig. 2, those procedures whose volume remained stable or gradually decreased are depicted. -Fig. 3 discloses a continuous decline in focal laser between 2011 to 2012 and 2018 to 2019 AYs. (2019 to 2020 AY data not available).

\section{Discussion}

Ophthalmology continues to experience technologic and therapeutic innovations that influence the medical and surgical management of eye diseases. Modern cataract surgery using phacoemulsification continues to become more efficient since its introduction in $1967 .^{17-19}$ Over the past
15 years, the adoption of intravitreal antivascular endothelial growth factor (anti-VEGF) therapy has all but supplanted laser treatment of retinovascular pathology and other diseases that cause retinal edema and neovascularization. Refinements to corneal transplantation, as well as expanded surgical treatments for glaucoma, have added new surgical procedures. As these advances have changed practice patterns among ophthalmologists, training programs incorporate new techniques into the surgical curriculum to graduate ophthalmologists with exposure and competence in these areas.

\section{Notable Trends by Role (Surgeon and Surgeon and Assistant)}

As might be expected, there were parallel trends for both the categories of $(\mathrm{S})$ and $(\mathrm{S}+\mathrm{A})$ for total procedures and specifically in the areas of cataract, other cataract, laser, and 


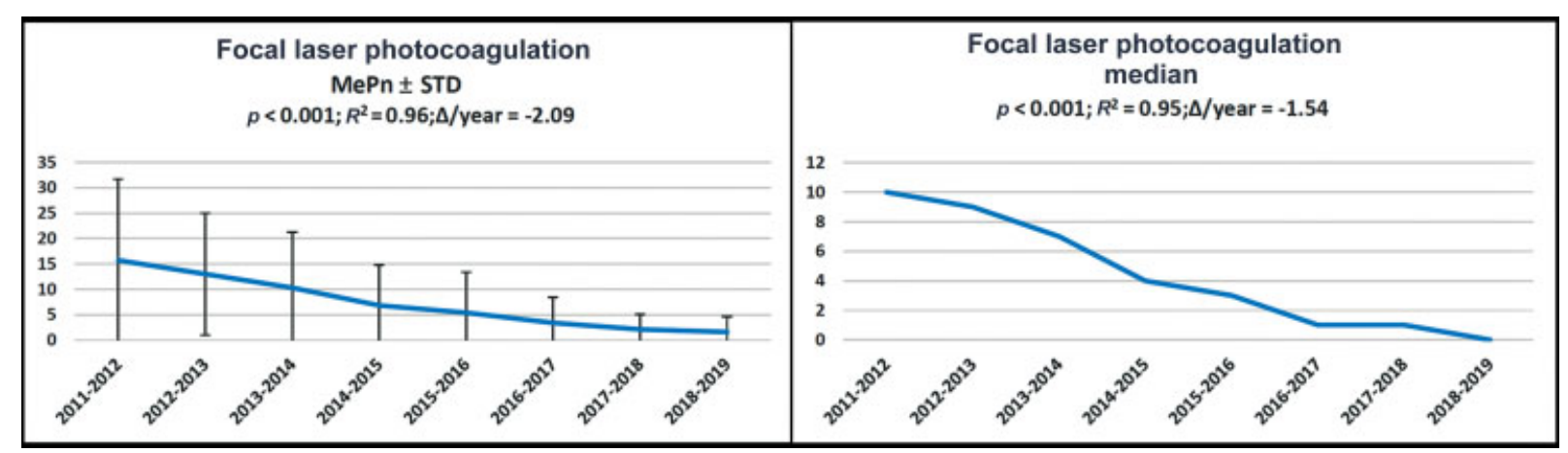

Fig. 3 Focal laser continuously declined from 2011 to 2012 to 2018 to 2019 AYs. (2019-2020 AY data not available). AY, academic year.

strabismus. The numbers for both $(\mathrm{S})$ and $(\mathrm{S}+\mathrm{A})$ significantly increased from 2011 to 2012 through the 2018 to 2019 AY but sharply decreased in the first pandemic year. In the areas of other cataract, laser, and strabismus, the numbers of procedures statistically declined for both the $(\mathrm{S})$ and $(\mathrm{S}+\mathrm{A})$ from 2011 to 2012 AY through the 2018 to 2019 AY and continued to decline between 2018 to 2019 and 2019 to 2020 , although not statistically significant. While glaucoma procedures fluctuated as $(S+A)$ during 2011 to 2012 through 2018 to 2019, the numbers statistically declined during 2019 to 2020 like the (S) group. The trends for oculoplastics and keratorefractive procedures were not parallel for $(S)$ and $(\mathrm{S}+\mathrm{A})$. The numbers of oculoplastics procedures for $(\mathrm{S}) \mathrm{did}$ not change between 2011 to 2012 and 2018 to 2019 but statistically declined between 2018 to 2019 and 2019 to 2020 , as we would expect for elective cases; however, for $(\mathrm{S}+\mathrm{A})$, oculoplastic procedures statistically declined between 2011 to 2012 and 2018 to 2019 and the pandemic year did not impact their numbers, reflecting the low volume for $(S+A)$. For keratorefractive procedures, the volume was initially parallel for both $(S)$ and $(S+A)$, steady between 2011 to 2012 and 2018 to 2019 and remained stable for (S) during 2019to 2020 but declined statistically for the $(S+A)$.

\section{Notable Trends during 2011-2019 Academic Years}

Our review of ACGME case log data over an 8-year period from 2011 to 2019 AYs reveals that the total number of procedures ophthalmology residents performed rose steadily. Cataract surgery and other retinal procedures (mainly intravitreal injections) were largely responsible for the rise in ophthalmology residents' procedural experience. Cataract surgery numbers as $(S)$ rose steadily and significantly from a mean of 152.8 to 208 per graduating resident, well above the minimum requirement of 86 . Factors that likely contribute to this significant rise include (1) more efficient surgical technique, (2) improved surgical technology, and (3) more efficient operating room workflow (all of which improve patient safety, reduce complications, and create capacity in the health delivery system), ${ }^{20-24}$ (4) an aging demographic in the United States resulting in an increased number of patients undergoing cataract surgery, ${ }^{25,26}$ and (5) better prepared beginning-resident-surgeons due to structured surgical curricula. ${ }^{27-30} \mathrm{~A}$ sixth factor may be the availability of national case log numbers that allows for benchmarking.
The cataract volume metric has become an influential measure by which programs and resident candidates make comparisons about surgical training. Presently, cataract surgery is clearly recognized as a skill in the purview of the general or comprehensive ophthalmologist having completed residency. The use of this measure may have created a socalled "arms race" where peer pressure among programs to have graduates attain successively higher cataract surgery numbers impact recruitment of future trainees. By prioritizing cataract surgery numbers to volumes well in excess of current minimum requirements, concerns for potentially negative consequences are emerging by using this metric as a program performance measure. Questions have been raised whether the resident graduates with large surgical volumes in certain procedures are receiving a sufficiently well-rounded experience to practice competently and autonomously as a general or comprehensive ophthalmologist. ${ }^{31}$ Although our study disclosed that a gradual decrease in subspecialty surgery experience occurred as cataract surgery experience rose, such association does not necessarily imply causality.

The increased focus on cataract surgery may also reflect an increased expectation for other ophthalmologic procedures to be performed by ophthalmologists who pursue further subspecialty training. The general trend toward increasing specialization in medicine is likely to narrow the scope of residency training and relegate subspecialty training to postgraduate fellowship programs. Further, the proliferation of fellowship programs brings more trainees into the surgical training environment and could potentially negatively impact the exposure of residents to subspecialty procedures. $^{32-36}$ Indeed a review of the mean and median case numbers as $(\mathrm{S}+\mathrm{A})$ for the areas of cornea, glaucoma, oculoplastic and orbit, retina-vitreous, and strabismus reveals a gradual decline in case numbers, while the stable numbers as ( $\mathrm{S}$ ) suggest less resident exposure as assistant surgeon to faculty in subspecialty surgeries. Explanations for this decrease may be the presence of fellows in the subspecialty operating rooms or more reliance on simulation to prepare residents to be primary surgeons.

Intravitreal drug delivery using anti-VEGF medications has displaced retinal laser as the primary mode of treatment for many retinovascular diseases, including neovascular agerelated macular degeneration, diabetic retinopathy, and 
retinal vein occlusion. The frequency of intravitreal injections has since significantly increased worldwide due to improved visual outcomes. ${ }^{37-41}$ This change in practice pattern is reflected in the AY 2011 to 2019 period when residents continue to perform an increasing number of intravitreal injections as (S). The number has risen steadily and significantly from a mean of 65.8 to 145.4 per graduating resident, numbers well above the minimum requirement of 10 (-Fig. 1); in this same time period, focal laser numbers declined ( - Fig. 3). The removal of focal lasers as a required procedure may have further deemphasized this procedure during training. The debate continues as to whether proficiency in performing intravitreal injections is within the scope of comprehensive ophthalmologists or preferentially those who complete additional subspecialty training in treating retinal disorders. Presently, factors that affect whether ophthalmologists, subspecialists, or physicians-intraining perform intravitreal injections include the local availability of subspecialty retina physicians, as well as differences in health care delivery systems, and payors of health care. Currently, the minimum requirement for other retinal procedures has not increased because, in general, comprehensive ophthalmologists are unlikely to perform intravitreal injections.

The increase in glaucoma procedures as $(\mathrm{S})$ may represent the contribution of minimally invasive glaucoma surgery in recent years. Increases were seen for YAG posterior capsulotomy and trabeculoplasty while cyclodestructive and iridotomy volumes remained stable. With increased cataract surgery numbers, an increase in YAG capsulotomy is not surprising since posterior capsular opacification is a common occurrence after cataract surgery. For the entire 9-year trend between 2011 and 2020, the median number of other glaucoma lasers, such as iridoplasty, was zero.

\section{Early Impact of COVID-19 Pandemic in 2019-2020 Academic Year}

In 2019 to $2020 \mathrm{AY}$, abrupt cessation of elective surgery nationwide in the Spring of 2020 due to the COVID-19 pandemic resulted in a sharp decline in cataract surgery experience as $(\mathrm{S})$ or $(\mathrm{S}+\mathrm{A})$ to levels comparable to 2013 to 2014 AY when the mean number of cataract surgeries as primary surgeon was 163.7 , twice the current minimum requirement of 86 . The decline in cataract surgery in 2019 to $2020 \mathrm{AY}$ was the largest contributing factor to the reduction in total surgical procedures to the levels seen in 2015 to 2016 AY. The halting of elective surgery most certainly impacted postgraduate year (PGY)-4 residents during a period of high surgical volume in their training. This occurred during their final 6 months of training when most PGY-4 residents are already well on their way to becoming proficient in cataract surgery. It will be important to examine the effects of the pandemic on subsequent resident classes negatively impacted during their formative years of training and potentially have had to grapple with curtailment of surgical activities. We postulate that programs that distribute their cataract surgery experience out over a greater period of time may be impacted less than those programs that concentrate a large portion of their surgery in the final year, or even within specific rotations during the final year of residency. Diversification of surgical experience over multiple rotations and years of training is one method for training programs to mitigate risk in the future.

While cataract surgical volume declined significantly during this period, nonelective treatments for patients at risk for irreversible visual loss without intervention were still provided care both in the office and operating room. Our data reveals that for all areas except cataract, the surgical experience remained relatively stable in 2019 to 2020 AY compared with 2018 to 2019 AY. For intravitreal injections, the numbers did not continue to climb but remained stable, and there is some reassurance that residents were able to maintain their surgical experience during the pandemic when caring for those patients whose conditions required nonelective procedures.

Our review also discloses that office procedures, such as laser surgery and intravitreal injection, are performed with little to no assistant experience. Declining numbers as assistant raises the question of whether residents are getting enough cases as assistant prior to operating as surgeon. Certain office based procedures, such as laser and intravitreal injections, do not lend themselves to assistance other than observation. Further, the recent proliferation of procedure simulation with the use of artificial (plastic or silicone) eyes and video or virtual simulation, as well as the program requirement, for a structured curriculum for simulation may have provided increasing resources to prepare residents for such procedures. ${ }^{15,42-47}$

Reviews of the ACGME case logs for ophthalmology residents from 2011 to 2019 AYs show significant increases in total procedures, primarily comprised of cataract surgery and intravitreal injections (other retinal procedures). These changes are likely due to more efficient care delivery, improved surgical technology, use of surgical simulation, and new practice patterns. We also noted a gradual decrease in resident exposure to subspecialty surgeries as $(S+A)$, suggesting less emphasis on exposure to subspecialty surgery. The resident experience as $(S)$ in subspecialty procedures mostly remained flat. Laser treatments such as YAG capsulotomy and trabeculoplasty increased while the rise of intravitreal injections curtailed panretinal laser photocoagulation and focal laser; the latter is no longer a requirement. These data suggest that required procedure minimums and resident achievement of these minimums should be periodically reevaluated as new technologies emerge and practice patterns change.

\section{Conclusion}

The temporary halting of elective procedures across the nation due to COVID-19 had a precipitous effect on resident cataract surgery experience. While the reduction in mean and median cataract surgical numbers were significant, the levels were similar to the 2013 to $2014 \mathrm{AY}$ when the mean was twice the current required minimum number. Other procedures remained stable. It should be recognized that there is likely to have been individual resident or 
institutional instances where case experiences were uneven. The long-term effects of the COVID-19 pandemic on resident surgical numbers is incompletely understood. The data presented here represent cases logged over a 3-year residency by graduates of 2019 to 2020 AY. Ongoing analysis of the surgical experience of graduating ophthalmology residents of the 2020 to 2021 and 2021 to 2022 AYs is necessary. These residents were in PGY-2 and PGY-3 at the beginning of the COVID-19 pandemic where experience in other procedure categories may have been affected. At the time of this writing, the COVID-19 pandemic is ongoing and uncertainty remains.

\section{Financial Support}

A.K.L.: the Unrestricted Grant, Research to Prevent Blindness, New York, New York; National Institute of Health Core Grant (grant. Number: P30 EY010572).

\section{Disclosure/Conflict of Interest}

A.K.L. and S.M.C. are volunteers and executive committee members for the Accreditation Council for Graduate Medical Education (ACGME) Review Committee for Ophthalmology; J.R.P. is a former Senior Vice-President, Head of Surgical Accreditation, and employee of the ACGME.

\section{References}

1 Zhu N, Zhang D, Wang W, et al; China Novel Coronavirus Investigating and Research Team. A novel coronavirus from patients with pneumonia in China, 2019. N Engl J Med 2020;382(08):727-733

2 Sohrabi C, Alsafi Z, O'Neill N, et al. World Health Organization declares global emergency: a review of the 2019 novel coronavirus (COVID-19). Int J Surg 2020;76:71-76

3 World Health Organization. WHO Director-General's opening remarks at the media briefing on COVID-19, March 11, 2020. Accessed September 3, 2021 at: https://www.who.int/directorgeneral/speeches/detail/who-director-general-s-opening-remarksat-the-media-briefing-on-covid-19-11-march-2020

4 Nicola M, Alsafi Z, Sohrabi C, et al. The socio-economic implications of the coronavirus pandemic (COVID-19): A review. Int J Surg 2020;78:185-193

5 Kurihara H, Bisagni P, Faccincani R, Zago M. COVID-19 outbreak in Northern Italy: viewpoint of the Milan area surgical community. J Trauma Acute Care Surg 2020;88(06):719-724

6 Brindle ME, Gawande A. Managing COVID-19 in surgical systems. Ann Surg 2020;272(01):e1-e2

7 American College of Surgeons. COVID-19: recommendations for management of elective surgical procedures surgical procedures. Accessed May 1, 2021 at: https://www.facs.org/covid-19/clinical-guidance/elective-surgery

8 American College of Surgeons. COVID-19: guidance for triage of non-emergent surgical procedures. Accessed May 1, 2021 at: https://www.facs.org/covid-19/clinical-guidance/triage

9 Center for Medicare and Medicaid Services. Non-emergent, elective medical services, and treatment recommendations. Accessed May 1, 2021 at: https://www.cms.gov/files/document/cms-nonemergent-elective-medical-recommendations.pdf

10 Center for Medicare and Medicaid Services. CMS releases recommendations on adult elective surgeries, non-essential medical, surgical, and dental procedures during COVID-19 response. Accessed May 1, 2021 at: https://www.cms.gov/newsroom/ press-releases/cms-releases-recommendations-adult-electivesurgeries-non-essential-medical-surgical-and-dental
11 Joint statement: roadmap for resuming elective surgery after COVID-19 pandemic. Accessed May 1, 2021 at: https://www. facs.org/covid-19/clinical-guidance/roadmap-elective-surgery

12 Accreditation Council for Graduate Medical Education. What we do. Accessed May 1, 2021 at: https://www.acgme.org/WhatWe-Do/Overview

13 Accreditation Council for Graduate Medical Education. Data collection systems. Accessed May 1, 2021 at: https://www.acgme.org/Data-Collection-Systems/Overview

14 Accreditation Council for Graduate Medical Education. Case log system. Accessed May 1, 2021 at: https://www.acgme.org/DataCollection-Systems/Case-Log-System

15 Accreditation Council for Graduate Medical Education. Program requirements for graduate medical education in ophthalmology. Accessed May 1, 2021 at: https://www.acgme.org/Portals/0/PFAssets/ProgramRequirements/240_Ophthalmology_2020_July.pdf? ver $=2020-06-30-144437-230$

16 Accreditation Council for Graduate Medical Education. Case log information: ophthalmology. Review committee for ophthalmology. Accessed May 1, 2021 at: https://www.acgme.org/Portals/ 0/PFAssets/ProgramResources/OPH_CaseLogInfo.pdf?ver=202101-28-153137-763

17 Kelman CD. Phaco-emulsification and aspiration. A new technique of cataract removal. A preliminary report. Am J Ophthalmol 1967;64(01):23-35

18 de Vries NE, Nuijts RM. Multifocal intraocular lenses in cataract surgery: literature review of benefits and side effects. J Cataract Refract Surg 2013;39(02):268-278

19 Nagy Z, Takacs A, Filkorn T, Sarayba M. Initial clinical evaluation of an intraocular femtosecond laser in cataract surgery. J Refract Surg 2009;25(12):1053-1060

20 Giese I, Kloek C. Learning from the past and looking toward the future in cataract surgery: how to evaluate innovations and incorporate into clinical practice. Int Ophthalmol Clin 2017;57 (04):11-19

21 Hoffman RS, Fine IH, Packer M. New phacoemulsification technology. Curr Opin Ophthalmol 2005;16(01):38-43

22 Stagg BC, Talwar N, Mattox C, Lee PP, Stein JD. Trends in use of ambulatory surgery centers for cataract surgery in the United States, 2001-2014. JAMA Ophthalmol 2018;136(01):53-60

23 Ben Hadj Salah W, Rousseau A, M'garrech M, Best AL, Barreau E, Labetoulle M. Assessment of the duration of surgery and patient turnover after the incorporation of a standardized intracameral combination of mydriatics and anesthetics for cataract surgery. J Cataract Refract Surg 2020;46(11):1487-1494

24 Hansen MS, Hardten DR. Financially efficient cataract surgery in today's healthcare environment. Curr Opin Ophthalmol 2015;26 (01):61-65

25 Erie JC, Baratz KH, Hodge DO, Schleck CD, Burke JP. Incidence of cataract surgery from 1980 through 2004: 25-year population-based study. J Cataract Refract Surg 2007;33(07): 1273-1277

26 Gollogly HE, Hodge DO, St Sauver JL, Erie JC. Increasing incidence of cataract surgery: population-based study. J Cataract Refract Surg 2013;39(09):1383-1389

27 Ellis EM, Lee JE, Saunders L, Haw WW, Granet DB, Heichel CW. Complication rates of resident-performed cataract surgery: Impact of early introduction of cataract surgery training. J Cataract Refract Surg 2018;44(09):1109-1115

28 Puri S, Srikumaran D, Prescott C, Tian J, Sikder S. Assessment of resident training and preparedness for cataract surgery. J Cataract Refract Surg 2017;43(03):364-368

29 Lotfipour M, Rolius R, Lehman EB, Pantanelli SM, Scott IU. Trends in cataract surgery training curricula. J Cataract Refract Surg 2017;43(01):49-53

30 Ament CS, Henderson BA. Optimizing resident education in cataract surgery. Curr Opin Ophthalmol 2011;22(01):64-67 
31 Liebman DL, McKay KM, Haviland MJ, Moustafa GA, Borkar DS, Kloek CE. Quantifying the educational benefit of additional cataract surgery cases in ophthalmology residency. J Cataract Refract Surg 2020;46(11):1495-1500

32 Gedde SJ, Budenz DL, Haft P, Tielsch JM, Lee Y, Quigley HA. Factors influencing career choices among graduating ophthalmology residents. Ophthalmology 2005;112(07):1247-1254

33 Dean WH, Grant S, McHugh J, Bowes O, Spencer F. Ophthalmology specialist trainee survey in the United Kingdom. Eye (Lond) 2019; 33(06):917-924

34 Rosenkrantz AB, Hughes DR, Duszak R Jr. Increasing subspecialization of the national radiologist workforce. J Am Coll Radiol 2020;17(06):812-818

35 Campbell RJ, Gill SS, Ten Hove M, et al. Strabismus surgical subspecialization: a population-based analysis. JAMA Ophthalmol 2015;133(05):555-559

36 Bell RH Jr. Graduate education in general surgery and its related specialties and subspecialties in the United States. World J Surg 2008;32(10):2178-2184

37 Sun JK, Jampol LM. The diabetic retinopathy clinical research network (DRCR.net) and its contributions to the treatment of diabetic retinopathy. Ophthalmic Res 2019;62(04):225-230

38 Mansour SE, Browning DJ, Wong K, Flynn HW Jr., Bhavsar AR. The evolving treatment of diabetic retinopathy. Clin Ophthalmol 2020;14:653-678

39 Lashay A, Riazi-Esfahani H, Mirghorbani M, Yaseri M. Intravitreal medications for retinal vein occlusion: systematic review and meta-analysis. J Ophthalmic Vis Res 2019;14(03):336-366
40 Schmidt-Erfurth UM, Pruente C. Management of neovascular agerelated macular degeneration. Prog Retin Eye Res 2007;26(04): 437-451

41 Andreoli CM, Miller JW. Anti-vascular endothelial growth factor therapy for ocular neovascular disease. Curr Opin Ophthalmol 2007;18(06):502-508

42 Ganne P, Krishnappa NC, Baskaran P, Sulaiman SM, Venkatesh R. Retinal laser and photography practice eye model: a cost-effective innovation to improve training through simulation. Retina 2018; 38(01):207-210

43 Moisseiev E, Loewenstein A. Simulation of laser retinopexy around retinal breaks for ophthalmologists in training. Ophthalmologica 2015;233(01):51-55

44 Moisseiev E, Michaeli A. Simulation of neodymium:YAG posterior capsulotomy for ophthalmologists in training. J Cataract Refract Surg 2014;40(02):175-178

45 Simpson SM, Schweitzer KD, Johnson DE. Design and validation of a training simulator for laser capsulotomy, peripheral iridotomy, and retinopexy. Ophthalmic Surg Lasers Imaging Retina 2017;48 (01):56-61

46 Muqit MMK, Aldington SJ, Scanlon PH. Quality improvement of laser treatment (QUILT). A new retinal laser simulation system for training in resource-poor countries. Retina 2019;39(07): 1430-1434

47 Yeh S, Chan-Kai BT, Lauer AK. Basic training module for vitreoretinal surgery and the Casey Eye Institute Vitrectomy Indices Tool for Skills Assessment. Clin Ophthalmol 2011; 5:1249-1256 